\title{
Gilles Declercq, Hippolyte calomnié: rhétorique et sophistique dans la tragédie racinienne
}

\section{Laura Rescia}

\section{Q OpenEdition}

1 Journals

\section{Edizione digitale}

URL: http://journals.openedition.org/studifrancesi/3721

DOI: 10.4000/studifrancesi.3721

ISSN: 2421-5856

\section{Editore}

Rosenberg \& Sellier

\section{Edizione cartacea}

Data di pubblicazione: 1 décembre 2012

Paginazione: 562-563

ISSN: 0039-2944

\section{Notizia bibliografica digitale}

Laura Rescia, «Gilles Declercq, Hippolyte calomnié: rhétorique et sophistique dans la tragédie racinienne»,

Studi Francesi [Online], 168 (LVI | III) | 2012, online dal 30 novembre 2015, consultato il 07 mars 2021. URL: http://journals.openedition.org/studifrancesi/3721 ; DOI: https://doi.org/10.4000/studifrancesi. 3721

Questo documento è stato generato automaticamente il 7 mars 2021.

\section{(c) (1)}

Studi Francesi è distribuita con Licenza Creative Commons Attribuzione - Non commerciale - Non opere derivate 4.0 Internazionale. 


\title{
Gilles Declercq, Hippolyte calomnié: rhétorique et sophistique dans la tragédie racinienne
}

\author{
Laura Rescia
}

\section{NOTIZIA}

GILLES DECLERCQ, Hippolyte calomnié: rhétorique et sophistique dans la tragédie racinienne, «Revue de l'Histoire Littéraire de France», n. 4, octobre 2011, pp. 819-836.

1 L'A. offre con questo articolo un nuovo e convincente esempio di lettura del discorso teatrale secentesco in relazione agli aspetti teorici della retorica classica e coeva: in questo caso, il trattato di retorica del père Lamy L'art de parler (1675) viene confrontato con Phèdre et Hippolyte di Racine, per indagare in particolare la retorica dell'insinuazione. Viene dunque presa in analisi la sequenza del testo raciniano a partire dal progetto di calunnia (III, 3) fino al processo di Hippolyte (IV, 2) da parte di Thésée, ovvero la crisi drammatica notoriamente provocata dal ritorno del Re a Trezène. Come conseguenza, da un lato l'accettazione di Phèdre, di lasciar dire a Enone, dall'altra il rifiuto di dire di Hippolyte. La prima posizione è raddoppiata da quella del Re, che delega a Nettuno l'esecuzione della sentenza di colpevolezza; sottolinea l'A. «la double subrogation détermine la catastrophe» e inscrive la tragedia nella crisi del segno in rapporto alla verità.

Thésée infatti cerca disperatamente un'evidenza, la cui assenza sottolinea l'incertezza ontologica del segno; questo atteggiamento cognitivo rinvia, nella teoria di Lamy, alla fattispecie della cecità della ragione, che sola consente la manipolazione sofistica. Enone elabora la sua calunnia a partire da un dispositivo sofistico: la sua menzogna è imbastita sulla manipolazione della dispositio, non nasce dall'inventio, è dunque interamente giocata sull'orientamento verosimile dei fatti. Una simile situazione si riproduce nel confronto tra Thésée e Hippolyte, dove l'ipotiposi si rivela supporto 
figurativo del processo immaginario, amplificando la teatralità con l'evocazione di immagini fantastiche o reali, ma sempre fallaci. L'A. confronta ancora la teoria di Lamy sull'esordio e sull'insinuazione, artificio retorico utile per stabilire l'accordo con l'uditorio quando questo si prospetta contrario a priori alla posizione che l'oratore vuole sostenere. È in questo senso che la retorica dell'insinuazione è apparentabile alla sofistica; ed è l'esame del caso di Ippolito di fronte a Teseo che consente all'A. di giungere ad una risposta circa le possibilità di manipolazione sofistica della realtà: la passione e il desiderio oscurano lo spirito di Thésée, minandone l'equilibrio cognitivo ed etico, e lo forzano ad interpretare ogni segno e ogni elemento linguistico come prova della colpevolezza del figlio. La tragedia mette in crisi il segno nel suo rapporto con la verità, il gioco dell'inganno assume valore ontologico.

3 Nella seconda metà del secolo XVII si manifesta quindi una doppia crisi, della croyance $\mathrm{e}$ dell'evidenza, identificabile tanto nel testo teorico quanto nella pièce raciniana: ma se Lamy rivela il suo ottimismo cartesiano, il drammaturgo dimostra che «la vérité demeure barrée du doute et de la manipulation». 